\title{
Integration of Physical and Mental Health: A Reproductive Health Necessity
}

\author{
Shreyashi Aryala ${ }^{\mathrm{a}, \mathrm{b}}$
}

Mental health is a determinant of physical health. This holds true largely in the perspective of female reproductive health. A woman has to go through various stages of mental and physical changes in her life from adolescence to pregnancy, puerperium and menopause. Studies have shown association of all these stages with various mental disorders like anxiety, mood disorders and depression.[1] In addition to these physiological changes, some women go through distressing life events like abortion, hysterectomy, sterilization and gender based violence. Unfortunately some suffer from chronic morbidities like sexually transmitted diseases, HIV/AIDS, fistulas, or pelvic organ prolapse. A few numbers of women also go through traumatic experiences in health care facilities during abortions, family planning counseling, childbirth or postpartum periods. All these have a potential for mood and anxiety disorders. [2][3] Regrettably, this association has been inconspicuously addressed.

The association of physical and mental health has been explored but implicated primarily on hormonal imbalance, namely oestrogen. This association has a biological basis but is partly guided by the stereotyped concept of blaming womens' problems on hormones. A direct link to hormonal imbalance is social issues which cannot be disregarded. Women in developing nations have low education and employment opportunities, have

a - Assistant Editor, Journal of Lumbini Medical College

b - Assistant Professor, Department of Obstetrics and Gynecology, Lumbini Medical College Teaching Hospital, Palpa

Corresponding Author:

Shreyashi Aryal

e-mail: shreyashiaryal@gmail.com

ORCID: http://orcid.org/0000-0002-6832-3530

How to cite this article:

Aryal S. Integration of Physical and Mental Health: A Reproductive Health Necessity. Journal of Lumbini Medical College. 2018;6(2):2 pages. DOI: 10.22502/jlmc.v6i2.275. Epub: 2019 Feb 10. extra unpaid workload of taking care of children and household tasks and also have lesser role in household and political decision making. Increase in the number of male migrant workers has added responsibilities to women who are left alone at home. All these factors add to mental burden of these women and when physical distress sets in, the effect is exponentially increased. In developing nations, this integration of gender and reproductive rights is still an unconsidered issue. But without a combined approach, women cannot be treated as a whole and an important aspect of womens' health will be missed.

The first approach to this integration would be to focus on research establishing the cause and effect of mental and reproductive health and addressing the socio-economic factors related to mental and physical well being of women. So far, research in this field has been done from the perspective of health care providers giving evidence on physical effects of reproductive health but we need studies that address issues from the mental health perspective of a female patient. Statistics on psychological effects of reproductive events like miscarriage, still birth, prolonged labor, or menopause have merely been addressed. There are studies which address mental health issues after humanitarian crisis like earthquake or civil war with some thought on sexual health, [4] but most scientists do not include reproductive changes in their models.[5][6] Our knowledge is very limited in these aspects. Research integrating these two aspects in relation to the socio economic context of the country needs to be enforced.

Another step to this integration would be to train health service providers to see beyond the physical symptoms. Screening tools need to be developed which detect mental disturbances in women who come seeking for physical ailments but otherwise keep their mental problems to themselves. Mechanisms to identify these silent sufferers have to be systematically integrated. Health centers are 
the first point of contact between rural women and service providers. They come to these facilities with their physical problems, so these centers can be developed as screening sites for mental symptoms. These women in early stages of mental disturbance can then be identified, counseled and referred for specialized care. Roles of primary health care professionals are to be defined in these aspects so that they can assess psychological wellbeing and provide comprehensive care to all women.

Finally, reproductive health services should target delivery of quality care which would be an atraumatic experience for women. Counseling, sensitivity, empathy, support and comfort are all a part of quality health care which might reduce the chances of developing mental symptomatology in a woman undergoing medical treatment. In low income nations, where basic health care is still a struggle, mental health of women is low priority but if we want to reduce gender disparity, then it is necessary to combine physical and mental heath and give our women a sound mind in a sound body.

There is a need of professional debates and policies designed to expand the existing reproductive health services to incorporate a mental health perspective within socio economic contexts. With some changes in health care policy, we might be able to achieve for our women, a pleasant sail-through from adolescence to menopause.

\section{REFERENCES:}

1. Health Organization, United Nations Population Fund, Key Centre for Women's Health in Society. Mental health aspects of women's reproductive health: a global review of the literature. World Health Organization; 2009.

2. Fisher J, Cabral de Mello M, Izutsu T, Vijayakumar L, BelferM,OmigbodunO.Mentalhealthaspectsofsexual and reproductive health in adolescents. International Journal of Social Psychiatry. 2011;57(1):86-97. DOI: 10.1177\%2F0020764010396697

3. Coleman R, Morison L, Paine K, Powell RA, Walraven G. Women's reproductive health and depression. Social psychiatry and psychiatric epidemiology. 2006 Sep 1;41(9):720-7. Epub 2006 Jun 22. PMID: 16794765 DOI: $10.1007 / \mathrm{s} 00127-006-0085-8$

4. Advocacy Forum and International Centre for Transitional Justice (ICTJ). Across the Lines: The Impact of Nepal's Conflict on Women. Kathmandu: Advocacy Forum and International Centre for Transitional Justice; 2010 p. 1-101. Available from: https://www.ictj.org/sites/default/files/ICTJ-NepalAcross-Lines-2010-English.pdf
5. Kane JC, Luitel NP, Jordans MJ, Kohrt BA, Weissbecker I, Tol WA. Mental health and psychosocial problems in the aftermath of the Nepal earthquakes: findings from a representative cluster sample survey. Epidemiology and psychiatric sciences. 2018 Jun;27(3):301-10. Epub 2017 Jan 9.PMID: 28065208 DOI: 10.1017/ $\underline{\text { S2045796016001104 }}$

6. Luitel NP, Kene J, Jordans M, Kohrt B, Tol W. Mental health problems in the aftermath of earthquakes in Nepal. European Psychiatry. 2016 Mar 1;33:S194-5. DOI: $10.1016 /$ j.eurpsy.2016.01.353 